\title{
PREPARATION OF TIN-DOPED MORDENITE BY MULTISTEP $p H$ TEMPLATE-FREE METHOD FOR THE TERT-ALKYLATION OF TOLUENE
}

\author{
Yang LI, ${ }^{\mathrm{a}}$ Zhiwei ZHOU, ${ }^{\mathrm{a} *}$ Juan QIN, ${ }^{\mathrm{b}}$ Zhirui LIU, ${ }^{\mathrm{a}}$ Hao HUANG, ${ }^{\mathrm{a}}$ Guang LIU ${ }^{\mathrm{a}}$ and Wenliang WU ${ }^{\mathrm{a}}$ \\ ${ }^{a}$ College of Chemical Engineering, Nanjing Tech University, Nanjing, 210009, P. R. China \\ ${ }^{b}$ Technology and Finance Service Center of Jiangsu Province, Productivity Center of Jiangsu Province, Nanjing 210042, P. R. China
}

Received August 10, 2018

Multistep $\mathrm{pH}$ template-free method was adopted to the preparation of the tin-doped mordenite (SnMOR) samples with the different framework-substituted tin species loadings, and their physical and chemical properties were studied by different characterizations. Their catalytic performances in the alkylation of toluene with tert-butyl alcohol were also investigated. The characterization results indicated that although the tin species can be incorporated into the framework of mordenite by the substitution of aluminum resulting in the decrease of relative crystallinity, the Lewis acidity would be promoted and the pore size would be dropped resulting in the increase of both toluene conversion and Para-tert-butyltoluene (PTBT) selectivity in the reaction. SnMOR (50) showed the highest catalytic performance,

whose toluene conversion of $36.3 \%$ and PTBT selectivity of $81.8 \%$, respectively, can be reached. And it showed good catalytic stability, and toluene conversion of $33.7 \%$ and PTBT selectivity of $87.2 \%$ would be obtained even after reacted for 5 times.

\section{INTRODUCTION}

Para-tert-butyltoluene (PTBT), as a toluene derivative, is widely used as a raw material for many nucleating agents, additives and modifiers, and it can also be used as an intermediate of medicines, perfumes, pesticides and alkyd resins. In the traditional procedure, the liquid acid, ${ }^{1}$ such as $\mathrm{AlCl}_{3}$ or $\mathrm{H}_{2} \mathrm{SO}_{4}$, was usually as the catalysts for the toluene alkylation with different agents, including isobutene, tert-butyl chloride or tert-butyl alcohol etc., which would suffer many inevitable disadvantages, for example equipment corrosion and difficulty transportation and recovery. ${ }^{2}$ To avoid the above problems,

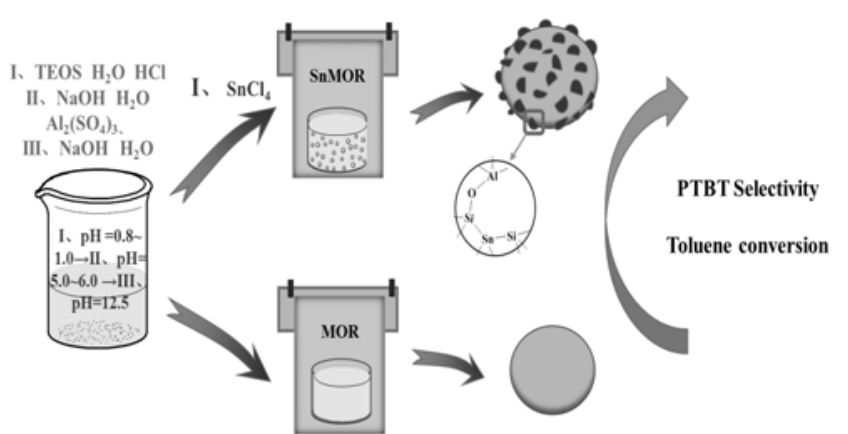

1. TEOS $\mathrm{H}_{2} \mathrm{O} \mathrm{HC}$

III. $\mathrm{NaOH} \mathrm{H} \mathrm{H}_{2} \mathrm{O}$

1.0 $\rightarrow$ II. $\mathrm{pH}$ $\mathrm{pH}=12.5$

\footnotetext{
* Corresponding author: wwl.njtech.edu.cn or zhiweizhou@njtech.edu.cn
}

some solid acid catalysts with high catalytic performance have been explored, where the mordenite is the most typical representation because of the dimension between molecular diameter of PTBT and its pore size resulting in the highest shape selectivity. ${ }^{3}$ On the contrary, the limited catalytic activity would be obtained owing to the relatively intrinsic low acidity, especially Lewis acidity, which has been proved to be beneficial to the toluene alkylation of tert-butyl alcohol. Therefore, the modified mordenite with increasing Lewis acidity would act as a promising catalyst for the tertbutylation of toluene.

Among the modification methods, the incorporation of the active components with high 
Lewis acidity into the framework with good catalytic stability would be a prospective strategy, and some heteroatom mordenites have been successfully prepared by replacing tetrahedrally coordinated sites of parent $\mathrm{Si}$ or $\mathrm{Al}$ atoms under controlled synthesis conditions, ${ }^{4-10}$ where the organic templates would frequently introduced because it plays a crucial role in zeolite synthesis for its structural orientation in the hydrothermal synthesis procedure resulting in increasing costs and serious pollutant emissions. Accordingly, it is essential to explore a new method without organic templates for the preparation of heteroatom zeolites. $\mathrm{La}(\mathrm{Ce})-\mathrm{ZSM}-5^{11}$ and $\mathrm{La}(\mathrm{Ce})-\mathrm{MCM}-22^{12}$ zeolites would be achieved by multiple $\mathrm{pH}$ adjustment procedures, including co-hydrolyzing and condensing tetraethyl orthosilicate and lanthanide salts in a weak acidic medium, followed by converting the synthetic gel to the basic conditions of hydrothermal crystallization owing to the reason that the allowable isolation and dispersion of the metal ions would promote the linkage between metal ions and silanol groups in the weak acidic condensation condition.

By incorporation of tetravalent tin species into the framework of carriers, such as mesoporous silicates, metal oxides or zeolites etc., have been proved to be solid Lewis acid catalysts with high catalytic performance in many organic processes. For example, $\mathrm{Sn}-\beta,{ }^{13} \mathrm{Sn}-\mathrm{Al},{ }^{14} \mathrm{Sn}-\mathrm{Ti}^{15}$ and $\mathrm{Sn}-\mathrm{Cu}-$ $\mathrm{Ti}^{16}$ catalysts have been successfully prepared and showed a good catalytic performance in the Baeyer-Villiger oxidation, Meerwein-PonndorfVerley reduction and glucose epimerization etc. Sn-MCM-41 catalyst can be used in the glycerol acetalization, ${ }^{17}$ trioses conversion ${ }^{18}$ and cellulose pyrolysis $^{19}$ etc. Consequently, the Lewis acidity of mordenite by incorporation of tin species into the framework should be promoted resulting in the increase of catalytic performance. On the other hand, the PTBT selectivity may be enhanced because of the decreased pore size resulting from the larger atomic diameter of tin than that of silicon or aluminum. ${ }^{20}$ Therefore, the SnMOR sample should be an efficient catalyst in the alkylation of toluene with alcohol. However, the heteroatom SnMOR zeolite in situ synthesis has not been widely reported so far, which may be attributed to the layered structure of mordenite itself and the longer Si-O-Sn bonds or much strain of bond angles resulting in the structural distortion. ${ }^{11}$

In this work, a series of SnMOR zeolite samples were synthesized by one-pot hydrothermal multistep $\mathrm{pH}$ template-free method, and the synthesized samples were subjected to XRD, XRF, UV-vis DRS, FT-IR, Py-IR, $\mathrm{N}_{2}$ sorption and SEM techniques to characterize the physical and chemical properties. The catalytic performance of the SnMOR was also investigated.

\section{RESULTS AND DISCUSSION}

\section{Catalyst characterization}

XRD patterns for different SnMOR samples are shown in Fig. 1. It can be seen that the typical characteristic diffraction peaks at $2 \theta$ of $19.6^{\circ}, 22.2^{\circ}$, $25.6^{\circ}$, and $26.2^{\circ}{ }^{21-23}$ for $\operatorname{SnMOR}(\infty)$ sample can be observed, suggesting the successful preparation of mordenite under the template-free conditions. Although these peaks intensities decreased gradually by the increasing incorporation of tin species, they can be obviously observed for SnMOR(30) even when the tin species is as high as 30 for the molar ratio of $\mathrm{Si} / \mathrm{Sn}$, indicating that the mordenite framework can be kept well. No characteristic diffraction peaks corresponding to the tin species, which is owing to the reason that they can be homogeneously incorporated into the framework of mordenite or were not detected by XRD patterns. However, the intensities of these characteristic peaks for $\mathrm{Sn} / \mathrm{MOR}(50)$ sample prepared by ion exchange were very low, suggesting its destruction of the mordenite framework, which is owing to the reason that the ion exchange process destroys the structure and crystallinity of MOR. In addition, the weak characteristic peaks centered at $2 \theta=26.6,33.9$ and $37.9^{\circ}$ appeared, indicataing that the $\mathrm{SnO}_{2}$ particles would be formed by ion exchange method. The I$\mathrm{Sn} / \mathrm{MOR}(50)$ sample exhibits a similar pattern to the $\mathrm{Sn} / \mathrm{MOR}(50)$ sample, indicating that $\mathrm{SnO}_{2}$ particles are formed on the surface.

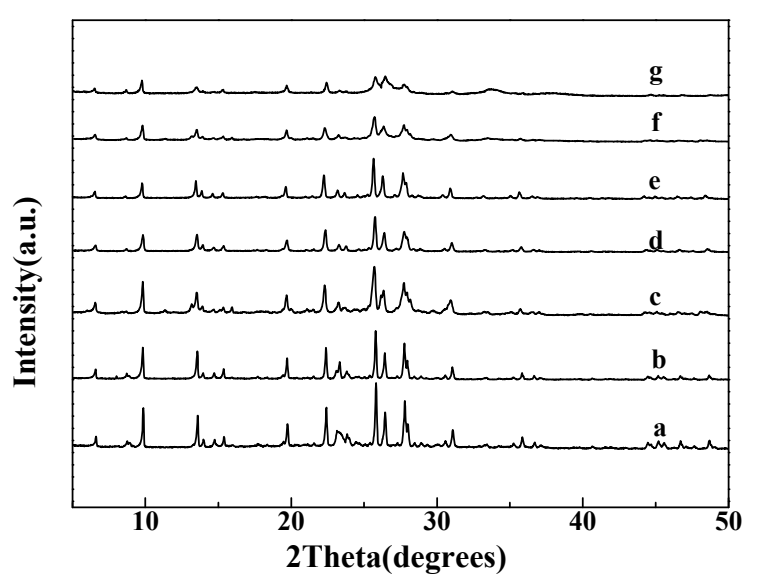

Fig. 1 - XRD patterns of different SnMOR: (a) $\operatorname{SnMOR}(\infty)$; (b) $\operatorname{SnMOR}(200) ; \quad$ (c) $\operatorname{SnMOR}(100) ; \quad$ (d) $\operatorname{SnMOR}(50)$; (e) SnMOR(30); (f) I-Sn/MOR(50) (g) Sn/MOR(50).

Table 1 was the textural parameters for different 
samples. From Table 1, it can be seen that the molar ratio of $\mathrm{SiO}_{2}$ to $\mathrm{Al}_{2} \mathrm{O}_{3}$ would be increased by the incorporation of tin species, further indicating that the tin species can be successfully incorporated into the framework of mordenite by the substitution of aluminum resulting in the increase of specific surface areas and the decrease of the pore volume and average pore diameter, which may be owing to the larger atomic radius of tin than aluminum. The molar ratio of silicon species to tin species is much higher than the feed theoretic value, suggesting the formation of nonframework tin species, which would be removed by filtration. For Sn/MOR(50) sample, the surface area is only $245 \mathrm{~m}^{2} \cdot \mathrm{g}^{-1}$, which can be attributed to the destruction of the framework resulting in the average pore size of $0.79 \mathrm{~nm}$ and pore volume of $0.09 \mathrm{~cm}^{3} \cdot \mathrm{g}^{-1}$. At the same time, the molar ratio of $\mathrm{SiO}_{2}$ to $\mathrm{Al}_{2} \mathrm{O}_{3}$ for $\mathrm{Sn} / \mathrm{MOR}(50)$ sample slightly increased from 14.1 to 16.3 , indicating that the dealumination would be happened in the ion exchange method, which may be owing to the weak acidity of aqueous tin chloride solution resulting in partical formation of substitution of aluminum species by tin species. The impregnated sample decreased in specific surface area and the pore size decreased, indicating that $\mathrm{SnO}_{2}$ was uniformly dispersed on the surface of the support. Sample I-Sn/MOR(50) is similar to sample Sn/MOR(50).

Figure 2 shows the FT-IR spectra of different SnMOR samples. Compared to the $\operatorname{SnMOR}(\infty)$ samples, a new weak absorption peak near $960 \mathrm{~cm}^{-1}$ for all the Sn-doped samples can be observed, which has been proved to the successful incorporation of heteroatoms into the zeolite framework. ${ }^{24-26}$ At the same time, the absorption peaks at 461,814 and $1102 \mathrm{~cm}^{-1}$ corresponding to the $\mathrm{Si}-\mathrm{O}-\mathrm{Si}$ bending vibration, the $\mathrm{Si}-\mathrm{O}-\mathrm{Si}$ symmetric stretching vibration and the $\mathrm{Si}-\mathrm{O}-\mathrm{Si}$ vibration stretching, respectively, are gradually red shifted to the lower wavenumber, which may be owing to the reason that the bond length of Sn-O$\mathrm{Si}$ is longer than that of $\mathrm{Si}-\mathrm{O}-\mathrm{Si},{ }^{11}$ further proving the successful incorporation of tin species into the mordenite framework.

Figure 3 shows the characteristic diffraction peaks of UV-vis DRS spectra for different SnMOR samples. Compared to $\operatorname{SnMOR}(\infty)$, a new strong absorption peak centered about at $210 \mathrm{~nm}$ corresponding to the tetrahedral incorporation of tin species for all the Sn-doped samples can be observed, which originates from the lone pair electrons on the oxygen atom to the charge of tetravalent tin $\left(\mathrm{O}^{2-} \rightarrow \mathrm{Sn}^{4+}\right)$, suggesting the successful incorporation of tin species into the mordenite framework. ${ }^{27}$ At the same time, the peak undergoes a certain degree of red shift with the tin species loading increasing because of the reduced crystallinity probably, which is consistent with the XRD results. When the molar ratio of silicon species to tin species increased up to 30 , a broad peak centered at 350-450 nm was emerged, which may be due to the formation of $\mathrm{SnO}_{2}$ particles ${ }^{28}$ undetected by XRD patterns. The absorption band centered at about $210 \mathrm{~nm}$ can also appear for the $\mathrm{Sn} / \mathrm{MOR}$ (50) sample because of the partical substitution of aluminum hole by tin species owing to the dealumination by aqueous tin chloride. But a broad band centered at $300-450 \mathrm{~nm}$ can also be observed, suggesting that some $\mathrm{SnO}_{2}$ particles have been formed, which is consistent with the XRD results, which is the same as $\mathrm{I}-\mathrm{Sn} / \mathrm{MOR}$ (50).

Figure 4 shows FT-IR spectra of pyridineadsorbed for different SnMOR samples. The absorption peaks centered at about $1455 \mathrm{~cm}^{-1}$ and $1545 \mathrm{~cm}^{-1}$ are corresponded to the effects between Lewis and Brønsted acid and pyridine molecules, respectively. ${ }^{29-31}$ It can be seen from Figure 6 that compared to the pure $\operatorname{SnMOR}(\infty)$ sample, the incorporation of tin species would be beneficial to the Lewis acidity, and it would further increase with the tin species loading increasing resulting in the catalytic performance in the tert-butylation of toluene with tert-butyl alcohol. For $\operatorname{Sn} / \operatorname{MOR}(50)$ sample, the Lewis acidity slightly increased, which may be owing to the substitution of aluminium species by tin species with stronger acidity. The Lewis acidity of the sample prepared by the impregnation method also increased.

The morphology of these samples was studied by SEM technique, and the results are shown in Figure 5. As can be seen from the figure, the morphology of the pure mordenite, namely SnMOR $(\infty)$, is elliptical and contains a small amount of amorphous structure. After their incorporation of tin species, the surface becomes gradually smooth and the particles with multilayered shapes are formed. When the tin species increased up to 100 , no obvious amorphous phase would be found, and the approximately particle size with $10 \times 4 \mu \mathrm{m}$ showed in Fig. 5 (g) was obtained. But with the further increasing of the tin species loading, the crystal morphology was tended to tetragonal and the crystallinity decreases slightly, and almost the amorphous phase for 
SnMOR(30) would be formed, which is consistent with the above characterization results, suggesting the excessive doping of tin species would severely affect the catalytic performance. The finely divided powder can be obtained for $\operatorname{Sn} / \operatorname{MOR}(50)$ and I$\mathrm{Sn} / \mathrm{MOR}(50)$ samples shown in Figure 5(f) owing to the partical collapse of mordenite framework by the ion exchange method.

Table 1

Textural parameters for different SnMOR samples

\begin{tabular}{|c|c|c|c|c|c|}
\hline Samples & $\begin{array}{c}\mathrm{S}_{\mathrm{BET}} \\
\left(\mathrm{m}^{2} \cdot \mathrm{g}^{-1}\right)^{\mathrm{a}}\end{array}$ & $\begin{array}{c}V_{p} \\
\left(\mathrm{~cm}^{3} \cdot \mathrm{g}^{-1}\right)^{b}\end{array}$ & $\begin{array}{c}D \\
(n m)^{c}\end{array}$ & $\begin{array}{c}\mathrm{Si} / \mathrm{Sn} \\
\text { (molar ratio) }^{\mathrm{d}}\end{array}$ & $\underset{\text { (molar ratio) }^{\mathrm{SiO}}}{\mathrm{SiO}_{2} / \mathrm{Al}_{2} \mathrm{O}_{3}}$ \\
\hline $\operatorname{SnMOR}(\infty)$ & 288 & 0.19 & 0.76 & $\infty$ & 14.1 \\
\hline SnMOR(200) & 328 & 0.19 & 0.72 & 245 & 14.5 \\
\hline SnMOR(100) & 342 & 0.17 & 0.67 & 192 & 16.4 \\
\hline SnMOR(50) & 356 & 0.16 & 0.64 & 156 & 17.1 \\
\hline SnMOR(30) & 363 & 0.13 & 0.54 & 88 & 17.9 \\
\hline I-Sn/MOR(50) & 268 & 0.12 & 0.77 & 181 & 16.1 \\
\hline Sn/MOR(50) & 245 & 0.09 & 0.79 & 178 & 16.3 \\
\hline
\end{tabular}

${ }^{\mathrm{a}} \mathrm{BET}$ surface areas; ${ }^{\mathrm{b}} \mathrm{P} / \mathrm{P}_{0}=0.99 ;{ }^{\mathrm{c}}$ Average pore size; ${ }^{\mathrm{d}} \mathrm{XRF}$

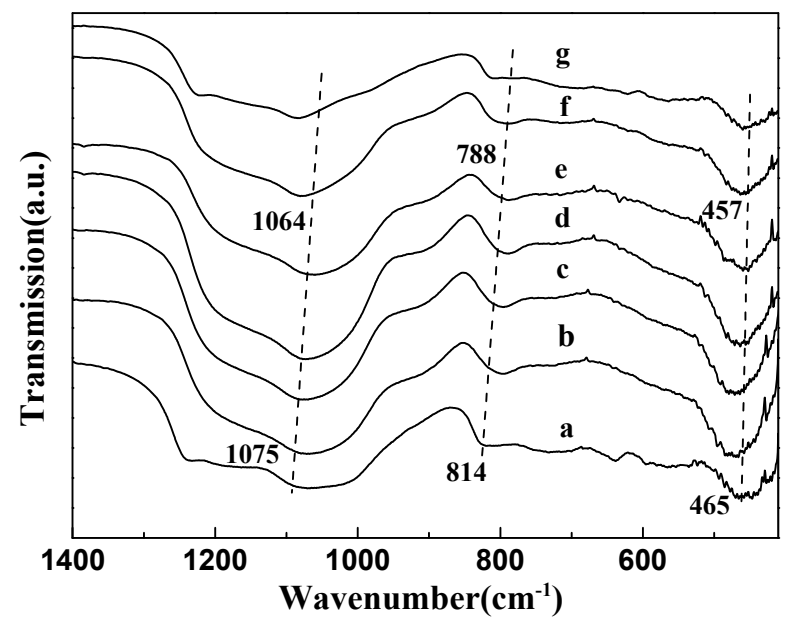

Fig. 2 - FT-IR spectra for different SnMOR samples: (a) SnMOR(o); (b) SnMOR(200); (c) SnMOR(100); (d) SnMOR(50); (e) SnMOR(30); (f) I-Sn/MOR(50) (g) Sn/MOR(50).

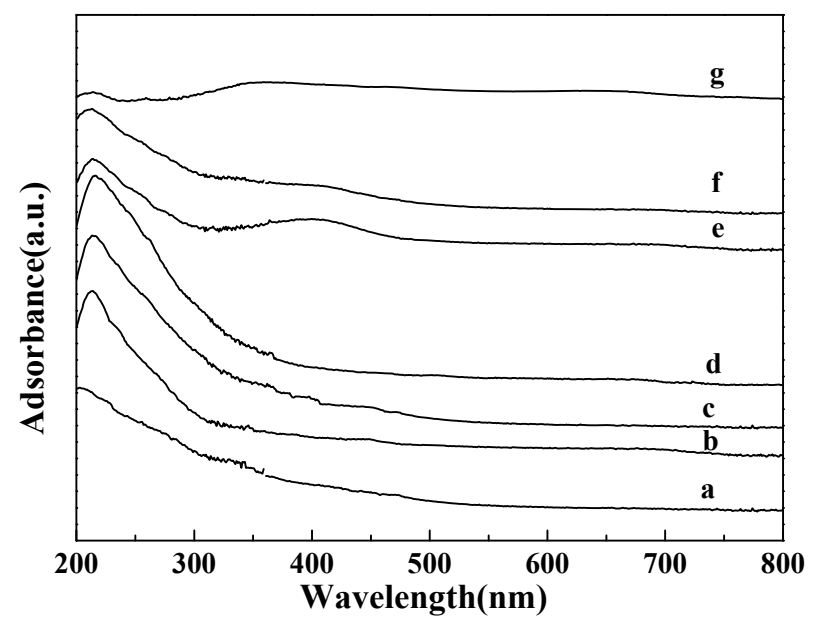

Fig. 3 - UV-vis DRS spectra of SnMOR: (a) SnMOR( $\infty$ ); (b) SnMOR(200); (c) SnMOR(100); (d) SnMOR(50); (e) SnMOR(30); (f) I-Sn/MOR(50) (g) Sn/MOR(50). 


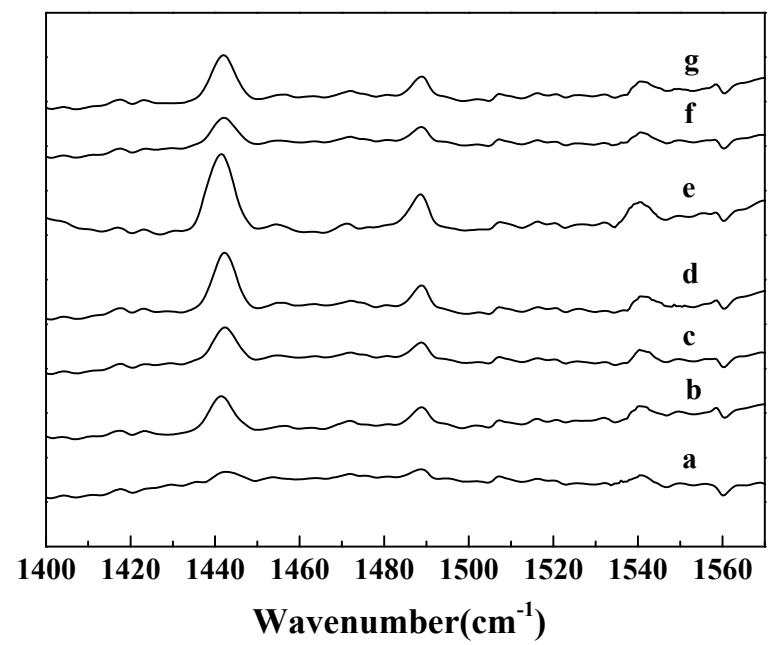

Fig. 4 - Py-IR spectra for SnMOR samples: (a) SnMOR( $\infty$ ); (b) SnMOR(200); (c) SnMOR(100); (d) SnMOR(50); (e) SnMOR(30); (f) I-Sn/MOR(50) (g) Sn/MOR(50).

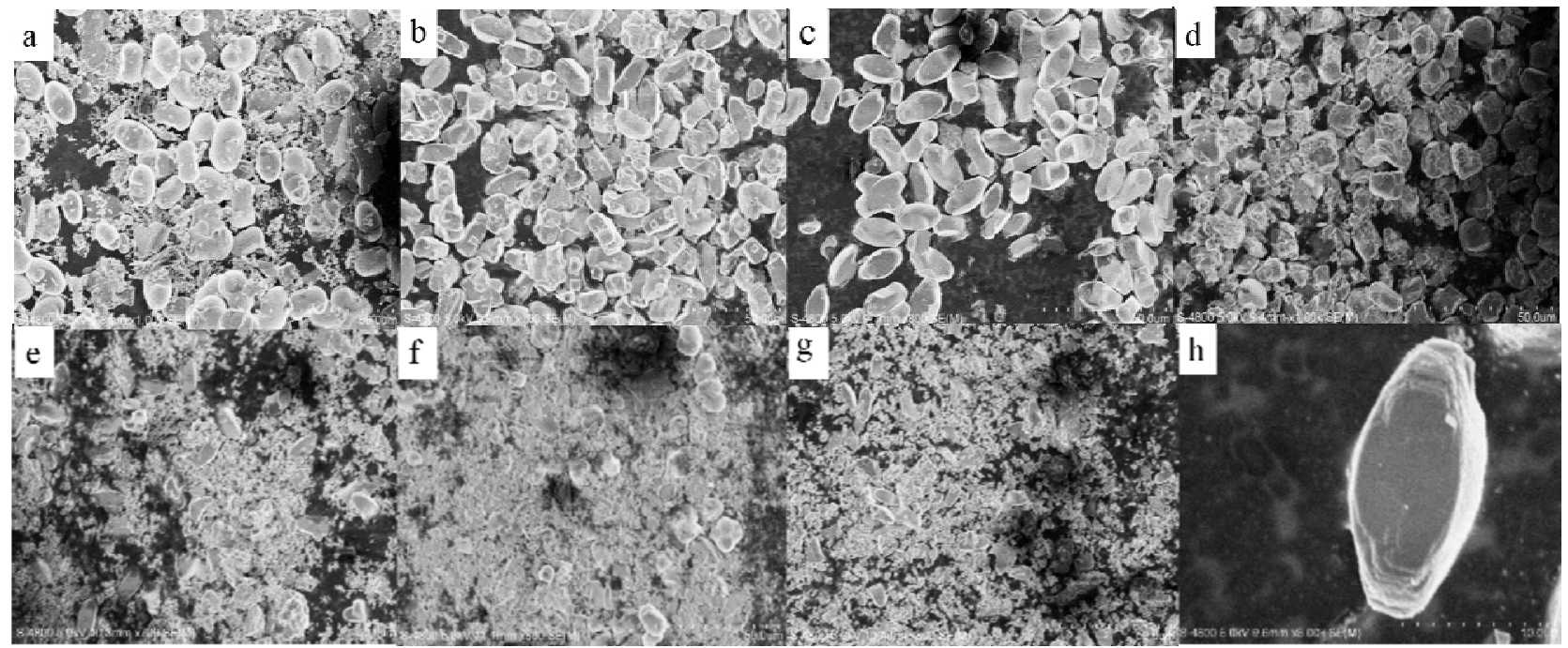

Fig. 5 - SEM images for different SnMOR samples: (a) SnMOR( $\infty$ ); (b) SnMOR(200); (c) SnMOR(100); (d) SnMOR(50); (e) SnMOR(30); (f) I-Sn/MOR(50) (g) Sn/MOR(50); (h) HR-TEM for SnMOR(100) sample.

\section{Catalytic performance}

The catalytic performances of different samples in the alkylation of toluene with tert-butyl alcohol are listed in Table 2. In all cases, the main products are identified as PTBT and meta-tert-butyltoluene (MTBT) because of the obstacle between methyl and voluminous tert-butyl group resulting in the difficulty for the formation of ortha-tert-butyltoluene (OTBT), and 3, 5-di-tert-butyltoluene (DTBT) were also be found, whose tert-butyl groups are both in the meta positions. It can be seen from Table 2 that toluene conversion of $20.8 \%$ and PTBT selectivity of $72.2 \%$ for $\operatorname{Sn}-\operatorname{MOR}(\infty)$ sample can be obtained. The incorporation of tin species would be beneficial to the toluene conversion and PTBT selectivity, which would be promoted from $20.8 \%$ and $72.2 \%$ to $36.3 \%$ and $81.8 \%$, respectively, over the $\operatorname{SnMOR}(50)$ sample with the appropriate physical or textural properties and Lewis acidity. With the tin species loading further increase up to 30 , both toluene conversion and PTBT selectivity over $\operatorname{SnMOR}(30)$ sample would be dropped, which would may be attributed to the smaller pore size than the molecular diameter of alkylated products resulting in the diffusion difficulty, although it has the highest acidity. However, only a toluene conversion of $6.8 \%$ and PTBT selectivity of $43.4 \%$ for $\mathrm{Sn} / \mathrm{MOR}(50)$ sample would be formed because of its destruction of framework by ion exchange of tin species although the tin species is almost the same as the SnMOR(50) sample. And the toluene conversion of $6.6 \%$ and PTBT selectivity of $53.2 \%$ for I$\mathrm{Sn} / \mathrm{MOR}(50)$ sample. 
Table 2

Catalytic performances of different samples in the alkylation of toluene with tert-butyl alcohol

\begin{tabular}{|c|c|c|c|c|c|c|}
\hline \multirow[t]{2}{*}{ Catalysts } & \multirow{2}{*}{$\begin{array}{c}\text { Toluene } \\
\text { conversion/\% } \%\end{array}$} & \multicolumn{4}{|c|}{ Distribution of products / $\mathrm{mol} \%$} & \multirow{2}{*}{$\begin{array}{c}\mathbf{S}_{\text {PTBT }} \\
1 \% \\
1 \%\end{array}$} \\
\hline & & $\begin{array}{c}\text { OTB } \\
\text { T }\end{array}$ & MTBT & PTBT & $\begin{array}{c}\text { Other } \\
\text { s }\end{array}$ & \\
\hline $\operatorname{SnMOR}(\infty)$ & 20.8 & 0 & 27.4 & 71.1 & 1.5 & 72.2 \\
\hline $\operatorname{SnMOR}(200)$ & 28.3 & 0 & 22.5 & 76.0 & 1.5 & 77.2 \\
\hline $\operatorname{SnMOR}(100)$ & 32.7 & 0 & 19.7 & 79.1 & 1.2 & 80.1 \\
\hline SnMOR(50) & 36.3 & 0 & 18.0 & 81.0 & 1.0 & 81.8 \\
\hline SnMOR(30) & 25.4 & 0 & 21.3 & 77.4 & 1.3 & 78.5 \\
\hline Sn/MOR(50) & 6.8 & 0 & 43.4 & 53.2 & 3.4 & 55.1 \\
\hline I-Sn-MOR(50) & 6.6 & 0 & 45.1 & 51.3 & 3.6 & 53.2 \\
\hline
\end{tabular}

$\mathrm{S}_{\text {PTBT }}$ : the molar ratio of PTBT to TBT. Reaction conditions: w(toluene $) / w($ catalyst $)=8$; Reaction temperature $453 \mathrm{~K}$; Initial pressure $0.8 \mathrm{MPa}$; $\mathrm{n}$ (toluene): $\mathrm{n}$ (tert-butyl alcohol): $\mathrm{n}(n$-hexane $)=1: 2: 6$; Reaction time $5 \mathrm{~h}$.

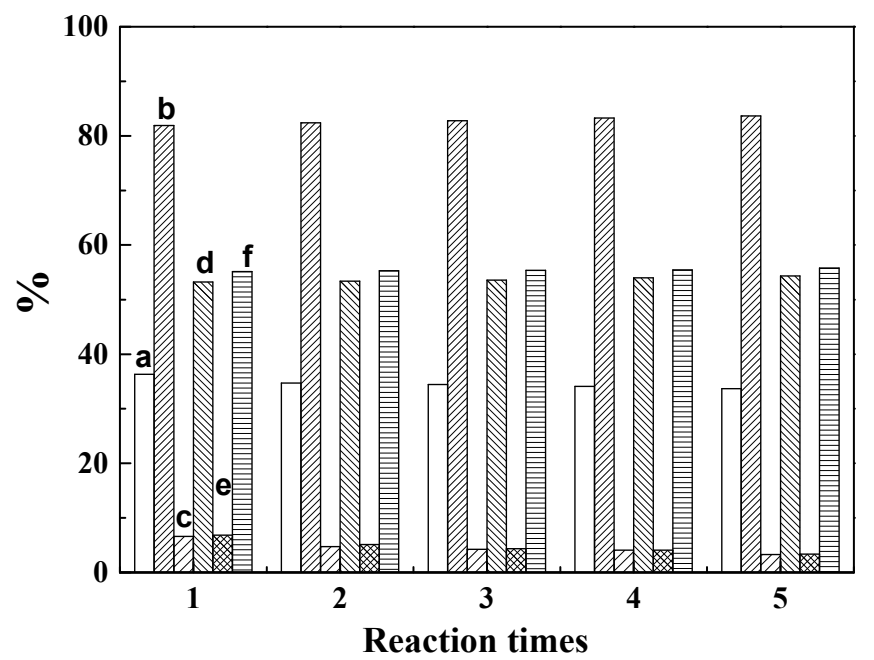

Fig. 6 - Catalytic stability for $\operatorname{SnMOR}(50)$ catalyst in the alkylation of toluene with tert-butyl alcohol Reaction conditions: $\mathrm{w}($ toluene $) / \mathrm{w}($ catalyst $)=8$; Reaction temperature $453 \mathrm{~K}$; Initial pressure $0.8 \mathrm{MPa} ; \mathrm{n}$ (toluene): $\mathrm{n}$ (tert-butyl alcohol): $\mathrm{n}(n$-hexane $)=1$ : 2: 6; Reaction time $5 \mathrm{~h}$. In the Fig 8, a, c, and e represent the toluene conversion of SnMOR (50), I-SnMOR (50), and Sn/MOR (50), respectively. b, d, and f represent the PTBT selectivity of SnMOR (50), I-SnMOR(50), and Sn/MOR (50), respectively.

Figure 6 was the catalytic stability for SnMOR(50) catalyst. It can be seen from Fig. 8 that toluene conversion decreased slightly and it can also reach up to $33.7 \%$ even after reacting for 5 times. On the contrary, PTBT selectivity would be slightly promoted, which may be owing to the shortened pore size by the coke resulting from the oligomerization of the isobutene and then carbonization. The above results indicated that the SnMOR(50) catalyst showed high catalytic stability, which would provide a good application prospect in the industrial process. However, after 5 cycles of use, the toluene conversion of the $\mathrm{Sn} / \mathrm{MOR}$ (50) sample and the I-Sn/MOR (50) sample were $3.4 \%$ and $3.3 \%$, respectively. May be caused by the loss of a large number of active components.

\section{EXPERIMENTAL}

\section{Preparation of catalysts}

The preparation of SnMOR samples with different tin species loadings by multistep $\mathrm{pH}$ template-free method is according to the previous literature, where tetraethyl orthosilicate (TEOS) and aluminum sulfate $\left[\mathrm{Al}_{2}\left(\mathrm{SO}_{4}\right)_{3}\right]$ were used as the silicon and aluminum source, respectively. As the typical preparation procedure, $6.4 \mathrm{~g}$ of TEOS was dissolved in $10.4 \mathrm{~g}$ of distilled water, and after complete dissolution to form a transparent solution, a certain amount of concentrated hydrochloric acid (98 $\mathrm{wt} \%$ ) was added until the $\mathrm{pH}$ was 0.8 1.0 , followed by the drop-wise addition of a certain amount of tin chloride aqueous solution with the molar percent of $1 \mathrm{~mol} / \mathrm{L}$. After stirred at $298 \mathrm{~K}$ for $24 \mathrm{~h}$, both $1.3 \mathrm{~g}$ of $\mathrm{Al}_{2}\left(\mathrm{SO}_{4}\right)_{3}$ and the appropriate amount of $\mathrm{NaOH}$ aqueous solution $(50$ $\mathrm{wt} \%$ ) were added to the mixture for adjusting the $\mathrm{pH}$ to 5.0 6.0 and it was stirred for another $12 \mathrm{~h}$. Finally, aqueous $\mathrm{NaOH}$ solution $(50 \mathrm{wt} \%)$ was further added to the above mixed solution to make the $\mathrm{pH}$ up to 11.9 , and it was transferred and 
then placed in an oven at $140^{\circ} \mathrm{C}$ for $5 \mathrm{~d}$. The sample was collected by filtration and washed, followed by drying at $100^{\circ} \mathrm{C}$ for $12 \mathrm{~h}$. The obtained samples were calcined at $550^{\circ} \mathrm{C}$ for $5 \mathrm{~h}$ and named $\operatorname{SnMOR}(\mathrm{n})$, where $\mathrm{n}$ is the molar ratio of $\mathrm{Si} / \mathrm{Sn}$ in the raw material. For comparison, the MOR zeolite was synthesized in the absence of tin chloride under the above preparation conditions, and the Sn/MOR (50) zeolite was also prepared by ion exchange method with $0.1 \mathrm{~mol} / \mathrm{L}$ aqueous tin chloride solution (1g: $10 \mathrm{ml})$. The sample was named as $\mathrm{I}-\mathrm{Sn} / \mathrm{MOR}(50)$ by impregnating $1 \mathrm{~g}$ MOR with $0.01 \mathrm{~mol} / \mathrm{L}$ aqueous tin chloride solution.

\section{Characterizations of catalysts}

The crystalline structures of the prepared samples were characterized by X-ray diffraction analysis (XRD) using a SmartLab diffractometer from Rigaku equipped with a $9 \mathrm{~kW}$ rotating anode $\mathrm{Cu}$ source at $40 \mathrm{kV}$ and $40 \mathrm{~mA}$ with a scan rate of $0.2^{\circ} \cdot \mathrm{s}^{-1}$ in the $2 \theta$ range from $5^{\circ}$ to $50^{\circ}$. Nitrogen sorption was measured at $77 \mathrm{~K}$ using a BEL SORP-MAX. The surface area was calculated by using the BET method, and the average pore size was obtained by BJH method. FT-IR spectra were recorded on a Nicolet 360 FT-IR instrument. The sample was pretreated in $10^{-2} \mathrm{~Pa}$ at $573 \mathrm{~K}$ for $3 \mathrm{~h}$ and then cooled down to room temperature for adsorbing pyridine for $2 \mathrm{~h}$. After that, the temperature was raised to $473 \mathrm{~K}$ for $1 \mathrm{~h}$ to remove the physisorbed pyridine, and the Py-IR spectra were measured at room temperature. Diffuse reflectance UV-vis spectra were measured on PE Lambda 950 ultraviolet-visible spectrophotometer. The wavelength range was from 200 to $800 \mathrm{~nm}$ and $\mathrm{BaSO}_{4}$ was used as a reference compound. Particle morphology of the samples was observed by SEM using a Hitachi S-4800 fieldemission scanning electron microscope (FESEM).

\section{Catalytic tests}

The catalytic alkylation of toluene with tert-butyl alcohol was carried out in a $0.1 \mathrm{~L}$ stainless steel autoclave with a magnetically driven impeller. $0.25 \mathrm{~g}$ of catalyst was added in the solution containing $2.0 \mathrm{~g}$ of toluene, $3.2 \mathrm{~g}$ of tert-butyl alcohol and $11.2 \mathrm{~g}$ of $\mathrm{n}$-hexane, and they were sealed and flushed for multiple times with nitrogen to replace air. Then the mixture was heated to the preset reaction temperature of $453 \mathrm{~K}$ with the initial pressure of $0.8 \mathrm{MPa}$. After reacting for $5 \mathrm{~h}$, the mixture was cooled down to room temperature, and the catalyst was removed by filtration. The reaction mixture was analyzed on a SP-6890 gas chromatograph equipped with a SE-30 column $(0.25 \mu \mathrm{m} \times 50 \mathrm{~m})$ and a flame ionization detector (FID). The catalytic stability was investigated by filtration without any further treatment in the next test.

\section{CONCLUSIONS}

The tin species incorporated mordenite, namely SnMOR, was successfully prepared via a multiple $\mathrm{pH}$ template-free method, and the tin species can be tetrahedrally incorporated into the framewoek of mordenite by subsititution of aluminum. Although the relative crystallinity would be dropped, both the increase of Lewis acidity and the decrease of pore size can be obtained resulting in the higher catalytic performance in the toluene alkylation with tert-butyl alcohol than pure mordenite. The catalytic performances in the toluene alkylation with tert-butyl alcohol for SnMOR catalysts are much higher than pure mordenite and $\mathrm{Sn} / \mathrm{MOR}$ samples. The prepared SnMOR(50) exhibited excellent catalytic stability even after repeated reaction for five times. This paper provides a valuable reference of a prospective catalyst for the tert-butylation of toluene with tert-butyl alcohol in the industrial process.

Acknowledgements. This work was supported by Jiangsu Planned Projects for Postdoctoral Research Funds (1302121C); Open Project of Beijing Key Laboratory for Enze Biomass and Fine Chemicals; Project Funded by the Priority Academic Program Development of Jiangsu Higher Education Institutions.

\section{REFERENCES}

1. S. Ostrowski and J. C. Dobrowolski, J. Mol. Catal. A-Chem., 2008, 293, 86-96.

2. A. Feller, I. Zuazo,A. Guzman, J. O. Barth and J. A. Lercher, J. Catal., 2003, 34, 313-323.

3. W. Alabi, L. Atanda, R. Jermy and S. Al-Khattaf, Chem. Eng. J., 2012, 195-196, 276-288.

4. Y. Liu, L. Xu, B. B. Xu, Z. K. Li, L. P. Jia, W. H. Guo, J. Mol. Catal. A-Chem., 2009, 297, 86-92.

5. A. Llanos, L. Melo, F. Avendaño, A. Montes and J. L. Brito, Catal. Today., 2008, 133, 20-27.

6. B. Xue, Y. X. Lin and L. J. Deng, Catal. Commun., 2009, 10, 1609-1614.

7. U. Mogera, M. Gedda, S. J. George and G. U. Kulkarni, ACS Appl. Mater. Inter., 2017, 9, 32065-32070.

8. E. Finocchio, T. Montanari, C. Resini and G. Busca, J. Mol. Catal. A-Chem., 2003, 204, 535-544.

9. A. Corma, M. E. Davis, Chemphyschem., 2004, 35, 304313.

10. B. K. G. Theng, E. F. Vansant and J. B. Uytterhoeven, Transactions of the Faraday Society, 1968, 64, 33703382.

11. J. Gu, Y. J. Wu, Y. H. Jin and J. Wang, J. Porous Mat., 2013, 20, 7-13.

12. Y. J. Wu, J. Wang, P. Liu, W. Zhang, J. Gu and X. J. Wang, J. Am. Chem. Soc., 2010, 132, 17989-17991.

13. A. Corma, L. T. Nemeth, M. Renz and S. Valencia, Nature, 2001, 412, 423-425.

14. Z. W. Zhou, P. C. Yu, J. Qin, W. L. Wu, L. Xu, Z.Q. Gu and X. Q. Liu, J. Porous Mat., 2015, 23, 239-245.

15. Z. W. Zhou, Y. Yu, P. C. J. Yu, Qin, S.S. Dai and W. L. Wu, React. Kinet. Mech. Cat., 2016, 120, 295-305.

16. Z. W. Zhou, J. Z. Wang, J. Qin, Y. Yu and W. L. Wu, J Porous Mat., 2018, 25, 835-843.

17. L. Li, T. I. Korányi, B. F. Sels and P. P. Pescarmona, Green Chem., 2012, 14, 1611-1619.

18. L. Li, C. Stroobants, K. Lin, P. A. Jacobs, B. F. Sels and P. P. Pescarmona, Green Chem., 2011, 13, 1175-1181.

19. C. Torri, I. G. Lesci and D. Fabbri, J. Anal. Appl. Pyrol., 2009, 85, 192-196.

20. P. Fejes, J. B. Nagy, K. Kovács and G. Vankó, Appl. Catal. A-Gen., 1996, 145, 155-184. 
21. Z. P. Ma, J. Y. Xie, J. L. Zhang, W. Zhang, Y. Zhou and J. Wang, Micropor. Mesopor. Mat., 2016, 224, 17-25.

22. B. Lu, T. Tsuda, H. Sasaki, Y. Oumi, K. Itabashi, T. Teranishi and T. Sano, Chem. Mater. 2004, 16, 286-291.

23. D. Zhou, X. H. Lu, J. Xu, A. A. Yu, J. Y. Li, F. Deng and Q. H. Xia, Chem. Mater. 2012, 24, 4160-4165..

24. E. G. Vaschetto, G. A. Pecchi, S. G. Casuscelli and G. A. Eimer, Micropor. Mesopor. Mat., 2018, 258, 71-78.

25. G. Q. Zou, D. Jing, W. Z. Zhong, F. P. Zhao, L. Q. Mao, Q. Xu, J. F. Xiao and D. L. Yin, Rsc $A d v$., 2016, 6, 37293734 .

26. M. Rasouli, H. Atashi, D. Mohebbi-Kalhori and N. Yaghobi, J. Taiwan Inst. Chem. E., 2017, 78, 438-446.
27. R. Grieken, C. Martos, M. S. Sánchez, D. Serrano, J. Melero, J. Iglesias and A. Cubero, Micropor. Mesopor. Mat., 2009, 119, 176-185.

28. M. Khaled, A. Chutia, J. Callison, P. P. Wells, E. K. Gibson, A. M. Beale, C. R. A. Catlow and R. Raja, J. Mater. Chem. A., 2016, 4, 5706-5712.

29. J. Q. Li, P. J. Miao, Z. Li, T. He, D. Z. Han, J. L. Wu, Z. Q. Wang and J. H. Wu, Energ. Convers. Manage., 2015, 93, 259-266

30. S. A. Al-Bogami and H. I. D. Lasa, Fuel. 2013, 108, 490501.

31. Y. S. Fan, Y. X. Cai, X. H. Li, H. Y. Yin and J. S. Xia, J. Ind. Eng. Chem., 2016, 25, 139-149. 